\title{
The classification of involuntary musical imagery: the case for earworms
}

Article

Accepted Version

This article may not exactly replicate the final version published in the APA journal. It is not the copy of record."

Williams, T. I. (2015) The classification of involuntary musical imagery: the case for earworms. Psychomusicology: Music, Mind and Brain, 25 (1). pp. 5-13. ISSN 0275-3987 doi: https://doi.org/10.1037/pmu0000082 Available at https://centaur.reading.ac.uk/40630/

It is advisable to refer to the publisher's version if you intend to cite from the work. See Guidance on citing.

To link to this article DOI: http://dx.doi.org/10.1037/pmu0000082

Publisher: American Psychological Association

All outputs in CentAUR are protected by Intellectual Property Rights law, including copyright law. Copyright and IPR is retained by the creators or other copyright holders. Terms and conditions for use of this material are defined in the End User Agreement.

\section{www.reading.ac.uk/centaur}

\section{CentAUR}

Central Archive at the University of Reading 
Reading's research outputs online 
The classification of involuntary musical imagery: the case for earworms Tim I Williams

University of Reading Berkshire Healthcare NHS Trust

Author Note

Tim I. Williams, Institute of Education, University of Reading, and Child and Adolescent Mental Health Services, Berkshire Healthcare NHS Trust, Reading, U.K.

The author is grateful to the editor and two anonymous referees for suggestions which have enhanced this paper significantly.

Correspondence concerning this article should be addressed to Tim Williams, Institute of Education, Institute of Education, London Road campus, 4 Redlands Road, Reading RG1 5EX

E-mail: timothy.williams@reading.ac.uk 


\begin{abstract}
Involuntary musical imagery (INMI) is the subject of much recent research interest. INMI covers a number of experience types such as musical obsessions and musical hallucinations. One type of experience has been called earworms, for which the literature provides a number of definitions. In this paper we consider the origins of the term earworm in the German language literature and compare that usage with the English language literature. We consider the published literature on earworms and conclude that there is merit in distinguishing between earworms and other types of types of involuntary musical imagery described in the scientific literature: e.g. musical hallucinations, musical obsessions. We also describe other experiences that can be considered under the term
\end{abstract} INMI. The aim of future research could be to ascertain similarities and differences between types of INMI with a view to refining the classification scheme proposed here. 
The classification of involuntary musical imagery: the case for earworms

Involuntary musical imagery (INMI) has attracted increasing interest recently following the work of Liikkanen (2008, 2009), Hemming (2009) Wammes \& Barušs (2009 - using the term spontaneous musical imagery), Beaman \& Williams (2010) and Williamson and her colleagues (Williamson et al., 2012). Much of this literature seems to be concerned with the same phenomena but due to a failure to agree a definition of both earworm and INMI, future research may become compromised. The aim of this paper is to propose a definition of earworms and set it within a preliminary classification of types of INMI, with the aim of enhancing scientific exploration of INMI through clearer description. The published literature seems to confuse these terms e.g. "Involuntary Musical Imagery (INMI) or "earworms" describes the experience whereby a tune comes into the mind and repeats without conscious control" (Williamson et al., 2012, p. 259) which appears to conflate a potential superordinate category INMI with one of its exemplars (earworms). Other authors appear to agree (e.g. figure 1 in Liikkanen, 2012b) that INMI should be a superordinate category perhaps using disturbance and vividness as classification dimensions (Liikkanen, 2012b). Further uncertainty has been introduced by the use of a number of other phrases as synonyms for earworms e.g. cognitively infectious musical agents (Sacks, 2007), sticky music (Sacks, 2007; Sacks, 2011), sticky tunes (Williamson, Liikkanen, Jakubowski \& Stewart, 2014), catchy tunes (Beaman \& Williams, 2010), as well as the original German word Ohrwurm (Eckert, 1979; Hemming, 2009). This paper reviews the definitions of earworms using German and English language literatures. Other languages have similar phrases as shown in Table 1 but we have not been able to find clear definitions in those languages (see Halpern \& Bartlett, 2011 for French and Italian; Cruz, 1998 and Orozco, 2001 for Spanish). Before defining earworms, we consider the definitions of INMI and propose that it is used as a superordinate category for a variety of experiences. Then other phrases or synonyms for earworms are considered before a brief overview of other types of 
INMI is presented. It is proposed that the term earworm be restricted to repeating instances of INMI that are experienced as internally generated and do not interfere significantly with everyday life, but may be accompanied by negative affect.

\section{The definition of INMI}

The definition of INMI follows from the definition of musical imagery quoted by Williamson et al. (2012, p. 260) "introspective persistence of a musical experience in the absence of direct sensory instigation of that experience". A number of studies have studied how participants can voluntarily use musical images such as in mental rehearsal or composition (see Williamson et al., 2012 for a brief overview). Thus voluntary musical imagery would be defined as a musical experience that was called to mind through active choice of the person in the absence of direct sensory instigation of that experience. Involuntary musical experiences would then be defined as musical experiences which occurred without the active choice of the person (i.e. involuntarily) and without the direct sensory instigation of the experience.

The published definitions of INMI contain a number of additional elements e.g. repetition, pathology and consciousness. Liikkanen (2008) defines INMI as "Conscious experience of music, familiar or novel that repeatedly goes over in one's mind during normal daytime awareness". Liikkanen (2012b, p.12) redefines the term "Involuntary Musical Imagery” as "a conscious experience of reliving a musical memory without deliberately attempting to do so" which removes the criterion of repetition. He goes on to state "[i]t is also known by other colloquial names such as earworms, sticky tunes, or tune in the head phenomenon" (Liikkanen 2012b, p.12) which implies that these are synonyms, and that the music is repeated. Williamson et al. (2012, p.3) defined INMI as "the experience of a piece of music that comes unbidden into the mind and repeats outside of conscious control" which implies repetition. Müllensiefen et al. (2014, p. 323) describe INMI as "conscious, internal experience of a musical excerpt in the absence of an external stimulus, which 
then goes on to repeat outside of conscious will or control". However, there is evidence from mind pop research that musical images may occur involuntarily once only (Elua, Laws \& Kvavilashvili, 2012), thus it seems unnecessarily restrictive to propose that the experience of INMI requires more than one recurrence. We propose therefore that INMI can refer to any involuntarily experienced musical image whether repeated or not.

In another paper Liikkanen (2012c, p. 237) proposes that INMI be restricted "to a non-clinical condition of unintentionally reviving the auditory image of a tune (Bailes, 2007; Brown, 2006; Sacks, 2007)". The non-clinical qualifier for INMI seems difficult to uphold when there is evidence in the literature for a variety of INMI experiences which are pathological e.g. musical obsessions or musical hallucinations. In addition other imagery research increasingly considers pathological and non-pathological to be varieties along a single continuum of experience differentiated by how they are evaluated by the person experiencing them rather than by an external judgment of pathology (Bentall, Baker \& Havers, 1991). Thus we suggest that the definition of INMI should not include any reference to pathology.

The use of the word "conscious" in the published definitions of INMI is unclear. Liikkanen (2008, p. 408), and Müllensiefen et al. (2014, p.323) use "conscious... experience" while Williamson et al. (2012, p.3) refers to "conscious control". As we will see there are involuntarily experienced musical images associated with changes in consciousness (e.g. musical dreams, musical palinacousis), so requiring a particular state of consciousness need not be part of the definition of INMI.

Thus the proposal in this paper is that Involuntary Musical Imagery (INMI) should be used as an overarching concept which includes a number of phenomena both pathological (e.g. musical hallucinations, musical obsessions) and non-pathological (e.g. earworms, musical mind-pops, musical images induced by experimental procedures). The definition would then be that INMI was the introspective occurrence of a musical experience in the absence of direct (i.e. musical) sensory 
instigation of that experience and the absence of choosing to recall that musical experience. It would not contain references to pathology nor would it specify whether the image repeated.

\section{Definitions of earworm}

Table 2 displays a number of published definitions of earworm or Ohrwurm from books, conference presentations or published papers. In the earliest paper, Eckert (1979) writing in German points out that earworm does not have a clear definition in German, but is widely used. He describes an earworm as a melody with or without words that imposes itself compulsively on the inner ear. La Motte (1993) also wrote about earworms in German in the context of identifying the types of music that became fixed in one's mind. He refers to voicing the melody as a common feature but does not offer a formal definition. He also describes the possibility that they might be repeated in one's mind after only one hearing, and that they might not be to one's liking. Hemming (2009) defined an Ohrwurm as humming a previously learnt tune, which implies voicing the tune out loud (“eine zuvor beiläufigaufgenommene Melodie wiederholt vor sich hinzusummen” p. 185) which contains the elements of previously heard melody (song), repeatedly and hummed.

Subsequently he concluded that an earworm is an involuntarily occurring memory/recall of a music that has previously been heard ("Ein "Ohrwurm" ist eine unwillkürliche auftretende Erinnerung an zuvor durch Anhören memorierte Musik.” p. 205). Table 2 shows the features of earworms as found in Hemming (2009) which suggests that he does not specify that the tune should repeat. Thus the German literature which explicitly uses the term Obrwurm regards it as an involuntary recollection which repeats and may be reproduced out loud by humming, singing or whistling.

Previously, some German authorities seemed to equate earworms with musical hallucinations. Thus Eckert (1979, p.40) describes his patient as having been diagnosed with "akustische Halluzination" by a psychiatrist. In Freud's Interpretation of Dreams (1900, p.299.) a patient is described in a footnote who appears to suffer from songs or pieces ... heard involuntarily or against 
her will ("Lieder oder Stücke ... unwillkürlich und widerwillig hört (halluziniert)" but he does not use the term “Ohrwurm”. Hemming's (2009) paper differentiates earworms from hallucinations as being non-pathological which he expands further in Hemming \& Altenmüller (2012, p. 420) "existing definitions of hallucinations (subjects believe in the existence of a sound-source outside of themselves...) as opposed to 'earworms' or involuntary musical imagery (subjects are aware there is no external sound-source as it is felt to be located inside the head) still need to be properly applied or clarified". In German then, Obrwurm is a repeating, involuntary piece of music which comes from inside the mind as distinct from hallucinations which repeat and are perceived as coming from outside.

In English, the Oxford English Dictionary online edition defines an earworm, as "A catchy tune or piece of music (or occas. a word or phrase) which persistently stays in a person's mind, esp. to the point of irritation" and is backed up by quotations dating back to 1991. However an earlier source is Rheingold (1987, p.8) who wrote:

The Germans use the word Ohrwurm (rhymes with "door worm," where the "w" is pronounced like a "v") to denote these cognitively infectious musical agents. Whenever somebody complains to you that he just can't keep the latest pop tune from running through his head, tell him he can dispel it by calling it by name and by thinking about the original German meaning, which captures some of the mnemonicalli [sic] parasitical connotations of the word, for Ohrwurm literally means "ear worm" and is also used to refer to a kind of worm that can crawl into the ear.

Thus in non-academic English language writing, the definition of an earworm contains ideas of repetitiveness and uncontrollability.

The academic literature in the English language begins with Bennett (2002, p.5) who defines an earworm as "previously heard music that, while consciously unintended, repeats uncontrollably 
and pervasively in thought". Cunningham, Downie and Bainbridge (2005) describe the earworm effect as a song that gets stuck in your head. Sacks' (2006) commentary piece uses a definition similar to that of Bennett (2002) without the qualifier of "pervasive". Levitin (2006) does not define earworms clearly, and prefers the use of the term stuck song syndrome, but describing it as a syndrome risks implying abnormality which does not fit with the ubiquity of earworms. Sacks (2007) devotes a whole chapter of his book to earworms or as he prefers to name them brainworms. He also regards them as somewhat pathological and emphasizes that they are both repetitive and somehow compelling and not entirely under conscious control. Liikkanen (2008) does not define earworm, but instead introduces the term INMI following Sacks (2007, p.35), i.e. both are repeating phenomena of the mind. The first suggested English language definition in a peer reviewed publication is that of Beaman \& Williams (2010) who refer to an inability to stop the experience and its repetitive form. Halpern \& Bartlett's (2011) similar study require stickiness in memory ("music playing over and over in your mind", p. 426) and that the recall is involuntary. Beaman \& Williams (2010) and Halpern \& Bartlett (2011) found that earworms typically did not last more than 24 hours and might include a whole song, rather than just a part of one. Most of Halpern \& Bartlett's (2011) respondents characterized the earworms as neutral, mixed or pleasant.

The Music, Mind and Brain research group at Goldsmiths University of London have also investigated earworms which their website defines as follows:

the experience of having a tune or a part of a tune stuck in your head. Often a person experiencing an earworm has no idea why a tune has popped into their head and has little control over how long it continues (http://www.gold.ac.uk/music-mind-brain/earwormproject/).

Once again this contains the ideas of repetition (stuckness) and lack of control. The titles of publications from this group often contain the word earworm (Floridou, Williamson \& 
Müllensiefen, 2012; Williamson \& Müllensiefen, 2012; Williamson \& Jilka, 2014, but not Williamson et al., 2014 or Müllensiefen et al., 2014). The publications which do refer to earworms conflate the concepts of INMI and earworms (e.g. Williamson \& Jilka, 2013; Williamson, et al., 2014; Müllensiefen et al., 2014).

Other authors have also confused INMI with earworms. Byron \& Fowles (2013, p.1) conflate earworms ("experiences of INMI are commonly called "earworms",) and INMI, while Beaty et al. (2013) use INMI (but not earworm) to mean repeating musical phrases occurring involuntarily. Hyman, et al. (2013, p.204) use earworm as a synonym for their preferred term "intrusive song" alongside "imagined music (Bailes, 2007), involuntary semantic memories (Kvavilashvili \& Mandler, 2004), and involuntary musical imagery (Liikkanen, 2008, 2012a; Sacks, 2007)”. In the English language literature there is confusion of the terms earworm and INMI. This is problematic, since it is clear that other experiences are involuntary images of music (e.g. musical obsessions) yet it is clear that earworms and other types of INMI are not the same to those experiencing them. This paper proposes therefore that the definition of an earworm is a piece of music that repeats a number of times in the head, without being recalled voluntarily. The piece of music can be either a part or a whole piece and may be known or novel. The earworm would then be a type of INMI alongside other types of INMI which we describe below. The benefit of using earworm is that it is a concise phrase that can be clearly understood in English and German scientific discourse, and corresponds well to everyday definitions in both languages. An initial characterization of earworms following work in Germany on Ohrwurm phenomena (Eckert, 1979; Hemming, 2009) and in the UK (Beaman \& Williams, 2010) and US (Halpern \& Bartlett, 2011) considered that the earworm was nonpathological. 


\section{Earworm Synonyms}

A number of synonyms for earworm have been used in the scientific and popular literatures (e.g. brainworms - Sacks, 2007; Stuck song syndrome - Levitin, 2006). Sacks (2007) explains that he prefers the term brainworm because it locates the phenomenon in the brain rather than in the ear. He does refer to brainworms as parts of melodies that repeat involuntarily in the mind. In his extended description he also describes brainworms which consist of whole compositions. Levitin's (2006) stuck songs are played back repeatedly and he advances a potential brain mechanism for them. Other synonyms are shown in Table 2, together with translations into other languages and their sources. Although some of these phrases have been presented in publications, none has achieved the frequency of use of earworm both in peer reviewed publications and in wider discourse such as blogs and webpages.

Brown (2006) described a form of involuntary musical experience which he called the perpetual music track, based on his own experiences. It consists of continuous or nearly continuous episodes of short sections of music which repeat many times. Brown (2006) describes it as occupying both waking thought and dreams, which are sometimes accompanied by movements and gestures similar to those that would be used were the music being played. The perpetual music track is only known in the scientific literature from Brown's (2006) account, although he describes other people who have experienced similar constant music in their minds, and correspondents of mine have described it affecting young people who often spend many hours listening to MP3 players. Wammes \& Barušs (2009) hint at the possibility that the perpetual music track may be more common than this one report suggests since items in their Musical Imagery Questionnaire referring to "hearing music in my head all the time" and "there is always music in my dreams" were endorsed by their respondents. Unfortunately they do not present frequency information for individual items 
of their questionnaire. In addition, one of the participants in Halpern \& Bartlett (2011) describes earworms lasting all day. The perpetual music track may differ from earworms, because it is a near continuous experience. In general as Beaman \& Williams (2010) showed, each earworm (a single section of music) lasts minutes to hours rather than being continuous and is intermittent, with one earworm being replaced by another at intervals. Further research with people who experience continuous or near continuous involuntary music would be helpful to differentiate the "perpetual music track" from earworms. It would be interesting to know how sleep experiences relate to those in the waking day as described by Brown (2006), since they might indicate a continuum of daytime and sleep INMI.

The most common synonym for earworm is however INMI, which is widely used by both the Goldsmiths group (e.g. (Floridou et al., 2012; Williamson and Müllensiefen, 2012; Williamson \& Jilka, 2014) and Liikkanen $(2008,2012)$. It is unclear to what extent INMI represents the same concept as the earworm. This paper proposes that earworms are a type of INMI, but are not the only type. In order to clarify communication however, it is important that scientists adopt agreed definitions which can then be used to ensure comparability of research studies. The absence of agreement may lead to confusion about what is being studied and results in some authors (e.g. Williamson et al., 2012, p. 260) referring to a range of words and phrases such "imagery [which] is ... spontaneous or involuntary musical imagery (INMI: Liikkanen, 2008), a phenomenon also dubbed "brain worms," "sticky music" (Sacks, 2007), "cognitive itch" (Kellaris, 2008), "sticky tunes" (Williamson, Liikkanen, Jakubowski \& Stewart, 2014) and "stuck song syndrome” (Levitin, 2006)".

\section{Musical Obsessions}

Obsessions are defined as "unwelcome and distressing ideas, thoughts, images or impulses that repeatedly enter your mind. They may seem to occur against your will. They may be repugnant to 
you, you may recognize them as senseless, and they may not fit your personality" (Goodman et al., 1989). They cause distress and are usually linked with a need to perform repetitive behaviors (compulsions). Music alone as an obsession in Obsessive Compulsive Disorder (OCD) is little studied and is only represented in the literature by case reports. Matsui et al. (2003) point out that musical obsessions are not seen as coming from outside the head but rather that they are generated by the person's own mind. The two cases described by Matsui et al. (2003) are interesting because they failed to respond to adequate doses of antipsychotic medication, but did respond to the most effective medication for OCD (clomipramine). Andrade (Andrade \& Rao, 1997; Pfizer \& Andrade, 1999) has also described two cases of musical obsessions, although the information in the case reports does not include clear descriptions of the compulsions involved. During the preparation of this paper, a review of descriptions of musical obsessions appeared (Taylor et al., 2014) which usefully distinguishes them from musical hallucinations, musical pseudohallucinations and musical palinacouses. They seem to be similar to some other forms of INMI in that they can vary over time, occur intermittently and may be related to recently heard music. Unlike other forms of INMI they promote avoidance of music that might trigger them, and often occur in conjunction with other symptoms of obsessive compulsive disorder (OCD) such as hand washing (Taylor et al., 2014).

\section{Musical Hallucinations}

In contrast to other types of INMI, musical hallucinations have been relatively well studied. Kumar et al. (2014, p. 86) offer the following definition:

Hallucinations are false percepts in the waking state that are not consequences of stimuli in the external environment, and can involve any sensory modality. Musical hallucinations $(\mathrm{MH})$ are a type of auditory hallucination characterized by perception of musical sounds in the absence of any external source of music. Their content is often familiar and can be instrumental, vocal or both. 
They tend to occur in older females with hearing impairment (Stewart et al., 2006), and the incidence of musical hallucinations in patients attending an audiology clinic was estimated at $2.5 \%$ (Cole, Dowson, Dendukuri \& Belzile, 2002). The experience is "so vivid that [the patients] initially feel that there is actual music playing in the room" (Stewart et al., 2006, p. 2548). Stewart et al. (2006) also point out that musical hallucinations are experienced as a coherent whole. Sacks (2007) provides a rich source of qualitative data about musical hallucinations during which one of his informants suggests that the quality that differentiates them from musical imagery is that they seem to be heard (as though they had an external source), unlike earworms which are not heard but are located in the mind (implying that they are thoughts Sacks, 2007, p. 50). They are often specific to the person's musical experiences and culture (Vitorovic and Biller, 2013) although they can include novel music (Warren \& Schott, 2006). The proposed distinction from earworms is that they are perceived as not being due to some thought process in one's own mind, but are perceived as due to an external source. They are likely to be associated with a variety of pathology including hearing impairment, brain insult or psychosis.

\section{Other types of Involuntary Musical Imagery}

\section{Musical mind pops}

Kvavilashvili (Kvavilashvili \& Anthony, 2012) has made the case for single occurrences of musical imagery to be regarded as musical mind pops rather than earworms. She specifically argues that one-off occurrences of a musical image differ from repeated occurrences of the same image. Her study found that people experience large numbers of musical mind pops and that they are primed by recent exposure to the stimulus (original music). She believes that the mind pops indicate 
activation of semantic networks of related concepts. Earworms would then be differentiated from musical mind pops by being repetitive rather than single occurrences.

Another type of single occurrence musical image has been demonstrated by Kraemer, Macrae, Green \& Kelley (2005) who showed that suddenly interrupting the playing of a well-known tune generated the impression of the music continuing. Brain imaging showed that the effect was due to continuing activation of the neural networks appropriate to listening to the music. It is unclear at this point whether this should be regarded as a means of inducing a musical mind pop, or whether a different mechanism is involved. One possibility is that it is a type of musical palinacousis, which is defined as the continued perception of music after it has stopped. Currently however it might be better to describe it as musical Cloze by analogy with tasks where people are required to complete printed texts which are known as Cloze tests (Taylor, 1953). In all three cases the phenomenon would fall within the definition of involuntary musical imagery introduced earlier.

Palinacousis is the perseveration of an external auditory stimulus. One review (Di Dio, Fields \& Rowan 2007) suggests that it is a sign of organic brain disease (e.g. epilepsy, stroke) and can involve perseveration of any auditory stimulus, including music. It would differ from earworms in requiring an immediately preceding musical stimulus, and not necessarily repeating. It is not a musical mind pop because it can only be induced by sounds and it seems likely to be different from the Kraemer et al. (2005) phenomenon because that study induced a continuation of music not a perseveration.

\section{Musical synesthesia}

Musical tone synesthesia could be regarded as a type of INMI. A recent review of synesthesia defines it as "a conscious experience in the absence of the normal preconscious sensory stimulation" (Ward, 2013, p.55), thus the hearing of musical tones as a result of seeing letters might be one example. About 3\% of the population experience synesthesia (Simner et al., 2006). Synesthesia can 
produce effects in both the same sensory domain (e.g. letters produce the sensation of colours both vision) or unrelated domains e.g. tastes produce colours. Of 1007 synesthetes who responded to the American Synesthesia Association only about 3\% experience sounds as a result of other sensory experiences (Day, 2014). Day (2014) also distinguishes between synesthetic effects of sounds and musical sounds (i.e. inducers of synesthetic experience) but does not distinguish between sounds and musical sounds in synesthetic experience. The synesthetic production of music is little studied in comparison to the more common varieties, although there are descriptions on the internet. In general the experience of synesthesia is a pleasant one but can sometimes be unpleasant (Hochel \& Milán, 2008). For instance, a journalist and composer has written that "speaking and hearing the words alone, each syllable they utter has a note, sometimes more than one. They speak in tunes and I can sing back their melody" (http://ljrich.wordpress.com/ accessed 25th May 2014). In Rich's case it seems that she has been able to use this skill to help her to compose music, whereas my correspondent felt that it was oppressive. In contrast, an email correspondent of the author was troubled by hearing musical tones every time she moved. The tones did not form a recognisable tune (differentiating it from both earworms and musical hallucinations), but were related to the type of movement (steps, arm movements) that she did. Other cases of synesthesia that result in tones or music coming to mind are reported in the literature, such as seeing colours causing the synesthete to hear musical tones (Pearce, 2007). Musical synesthesia then is the production of musical sounds in response to stimulation in another sensory domain or type. Similarly to some earworms the music produced is novel, involuntarily produced, but does not repeat and can be induced reliably.

\section{Musical dreams}

Dreams are usually not subject to voluntary control, with the possible exception of lucid dreams. Uga, Lemut, Zampi, Zilli, \& Salzarulo (2006) compared the dreams of musicians and non- 
musicians and found that musicians typically had about twice as many musical dreams as nonmusicians. This corresponds with other work which suggests that people with musical interests and activities will have more involuntary musical images than non-musically trained people (Beaman \& Williams, 2010; Müllensiefen et al., 2014). Although most music recalled in dreams is familiar, Uga et al. (2006) found that their respondents reported that musical dreams might contain unusual variants of the familiar music or even unfamiliar music. Musical dreams differ from earworms in that they occur in a non-waking stage of consciousness.

\section{Conclusions}

In summary, this paper proposes that the term involuntary musical imagery (INMI) refers to any and all music that is heard in the mind without being deliberately recalled. The term INMI would then cover the following phenomena: earworms, musical mind pops, musical obsessions, musical hallucinations, musical palinacouses, musical synesthesia, musical Cloze and musical dreams (see figure 1). There may be other types of INMI that have not been described here such as intraictal music in epilepsy although we are not aware of descriptions of such experiences.

The term earworm would be restricted to repeating occurrences of INMI, in contrast to musical mind pops or musical Cloze. Earworms would not be considered pathological as so many people experience them and they are not distressing, which would distinguish them from musical obsessions and musical hallucinations. Musical palinacousis is not clearly pathological, but the descriptions in the literature suggest that it is associated with brain pathology. They occur in waking states, rather than in sleep, unlike musical dreams. However further research may undermine this distinction if Brown's perpetual music track is seen as an earworm experience. Musical synesthesia differs from earworms because it is induced by other sensory stimuli, although it is a form of INMI.

If these definitions (of INMI and earworm) are accepted, it has implications for the literature published to date. For instance, studies of induction of INMI (e.g. Liikkanen, 2012a; Hyman et al., 
2013) would need to specify whether one instance of a musical piece had occurred or whether there were repeats of that piece. Only if repeats were recorded could it be regarded as inducing earworms, as opposed to say musical mind pops.

In summary, this paper has differentiated INMI from earworms and suggested that a number of other experiences should also be regarded as INMI. Future research can serve to identify what characteristics at the phenomenological, cognitive and brain structure and function levels are characteristic of which INMI. There are for instance types of INMI which are associated with pathology (musical hallucinations, musical palinacouses and musical obsessions) which are differentiable at the level of phenomenology, but a question remains as to how the brain structures relate to the experiences. Similar questions can be asked about musical dreams, musical mind pops and earworms. 


\section{References}

Andrade, C., \& Rao, N. (1997). Musical obsessions: a case report. Indian journal of psychiatry, 39(2), 178.

Bailes, F. A. (2007). The prevalence and nature of imagined music in the everyday lives of music students. Psychology of Music, 35(4), 555-570.

Beaman, C. P., \& Williams, T. I. (2010). Earworms ('stuck song syndrome’): Towards a natural history of intrusive thoughts. British Journal of Psychology, 101, 637-653. doi:

10.1348/000712609X479636

Beaty, R. E., Burgin, C. J., Nusbaum, E. C., Kwapil, T. R., Hodges, D. A., \& Silvia, P. J. (2013). Music to the inner ears: Exploring individual differences in musical imagery. Consciousness and Cognition, 22(4), 1163-1173. doi: 10.1016/j.concog.2013.07.006

Bennett, S. (2002). Musical Imagery Repetition (MIR). M.Phil., Cambridge, Cambridge, UK. Retrieved from www.zingle.org/Musical_Imagery_Repetition/

Bentall, R. P., Baker, G. A., \& Havers, S. (1991). Reality monitoring and psychotic hallucinations. British Journal of Clinical Psychology, 30(3), 213-222. doi: 10.1111/j.2044-8260.1991.tb00939.x

Brown, S. (2006). The Perpetual Music Track: The Phenomenon of Constant Musical Imagery. Journal of Consciousness Studies, 13, 43-62.

Byron, T. P, \& Fowles, L. C. (2013). Repetition and recency increases involuntary musical imagery of previously unfamiliar songs. Psychology of Music, 0305735613511506.

Cole, M. G., Dowson, L., Dendukuri, N., \& Belzile, E. (2002). The prevalence and phenomenology of auditory hallucniations among elderly subjects attending an audiology clinic. International Journal Of Geriatric Psychiatry, 17, 444-452. 
Cruz, P. L. (1998). "La canción comprometida en el aula de ingles." Encuentro. Revista de Investigación e Innovación en la clase de idiomas 10: 99. Retrieved from http://pliegos.culturaspopulares.org/encuentro/textos/10.10.pdf

Cunningham, S. J., Downie, J. S., \& Bainbridge, D. (2005, September). “The Pain, The Pain”: Modelling music information behavior and the songs we hate. Paper presented at the Sixth International Conference on Music Information Retrieval, London, U.K. Retrieved from http://researchcommons.waikato.ac.nz/handle/10289/79.

Day, S. (2014, 16 June 2013). Types of synesthesia Retrieved 22/08/2014, from http://www.daysyn.com/Types-of-Syn.html

De La Motte, D. (1993). Melodie. Ein Lese- und Arbeitsbuch München: dtv.

Di Dio, A. S., Fields, M. C., \& Rowan, A. J. (2007). Palinacousis—auditory perseveration: two cases and a review of the literature. Epilepsia, 48(9), 1801-1806.

Eckert, C. (1979). Der „Ohrwurm “: Zur Psychopathologie des Alltagslebens. Psyche, 33(6), 545-550.

Elua, I., Laws, K. R., \& Kvavilashvili, L. (2012). From mind-pops to hallucinations? A study of involuntary semantic memories in schizophrenia. Psychiatry research, 196(2), 165-170.

Floridou, G. A., Williamson, V. J., \& Müllensiefen, D. (2012). Contracting Earworms: The Roles of Personality and Musicality. Paper presented at the 12th International Conference on Music Perception and Cognition, Thessaloniki, Greece. Retrieved from http://www.researchgate.net/profile/Victoria_Williamson/publication/235417631_Contrac ting_Earworms_The_Roles_of_Personality_and_Musicality/links/0fcfd5116185c5013d0000 00.pdf

Freud, S. (1900). Die Traumdeutung. Leipzig, Germany: Franz Deuticke. 
Goodman, W. K., Price, L. H., Rasmussen, S. A., Mazure, C., Delgado, P., Heninger, G. R., \& Charney, D. S. (1989). The Yale-Brown Obsessive Compulsive Scale. II. Validity. Arch Gen Psychiatry, 46(11), 1012-1016.

Halpern, A. R., \& Bartlett, J. C. (2011). The persistence of musical memories: A descriptive study of earworms. Music Perception, 28(4), 425-432.

Hemming, J. (2009). Zur Phänomenologie des Ohrwurms. Musikpsychologie, 20, 184-207.

Hemming, J., \& Altenmüller, E. (2012). When an everyday-phenomenon becomes clinical: The case of long-term 'earworms'. Paper presented at the 12th International Conference on Music Perception and Cognition, Thessaloniki, Greece.

Hochel, M., \& Milán, E. G. (2008). Synaesthesia: The existing state of affairs. Cognitive neuropsychology, 25(1), 93-117.

Hyman, I. E., Burland, N. K., Duskin, H. M., Cook, M. C., Roy, C. M., McGrath, J. C., \& Roundhill, R. F. (2013). Going Gaga: Investigating, Creating, and Manipulating the Song Stuck in My Head. Applied Cognitive Psychology, 27(2), 204-215. doi: 10.1002/acp.2897

Kellaris, J. J. (2008). Music and consumers. In C. P. Haugtvedt, P. Herr, \& F. R. Kardes (Eds.), Handbook of consumer psychology (pp. 837-856). New York: Taylor \& Francis.

Kraemer, D. J., Macrae, C. N., Green, A. E., \& Kelley, W. M. (2005). Musical imagery: sound of silence activates auditory cortex. Nature, 434(7030), 158-158.

Kumar, S., Sedley, W., Barnes, G. R., Teki, S., Friston, K. J., \& Griffiths, T. D. (2014). A brain basis for musical hallucinations. Cortex, 52, 86-97. doi: 10.1016/j.cortex.2013.12.002

Kvavilashvili, L., \& Anthony, S. H. (2012). When do Christmas songs pop into your mind?: Testing a long term priming hypothesis. Paper presented at the 53rd Annual Meeting of the Psychonomic Society, Minneapolis, Minnesota, USA. 
Kvavilashvili, L. \& Mandler, G. (2004). Out of one’s mind: A study of involuntary semantic memories. Cognitive Psychology, 48(1), 47-94.

Levitin, D. J. (2006). This is your brain on music: The science of a buman obsession. New York: Penguin.

Liikkanen, L. A. (2008). Music in everymind: Commonality of involuntary musical imagery. Paper presented at the Proceedings of the 10th International Conference on Music Perception and Cognition (ICMPC10), Sapporo, Japan. Retrieved from http://1.kryptoniitti.com/lassial/files/publications/080904-Music_in_everymind_pdf.pdf

Liikkanen, L. A. (2009). How the mind is easily booked on musical imagery. Paper presented at the 7th Triennial Conference of European Society for the Cognitive Sciences of Music, Jyväskylä, Finland. Retrieved from https://jyx.jyu.fi/dspace/bitstream/handle/123456789/20890/urn_nbn_fi_jyu2009411274.pdf

Liikkanen, L. A. (2012a). Inducing involuntary musical imagery: An experimental study. Musicae Scientiae, 16(2), 217-234. doi: 10.1177/1029864912440770

Liikkanen, L. A. (2012b) Involuntary Music Among Normal Population and Clinical Cases. Advances in clinical neuroscience and rehabilitation, 12(4), 12-14.

Liikkanen, L. A. (2012c). Musical activities predispose to involuntary musical imagery. Psychology of Music, 40, 236-256.

Liikkanen, L. A. (2012d). New Directions for Understanding Involuntary Musical Imagery. Paper presented at the 12th International Conference on Music Perception and Cognition (ICMPC) and 8th Triennial Conference of the European Society for the Cognitive Sciences of Music (ESCOM), Thessaloniki, Greece. Retrieved from http://1.kryptoniitti.com/lassial/files/publications/120725-Understanding_INMI.pdf Margulis, E. H. (2014). On Repeat: How Music Plays the Mind. Oxford, Oxford University Press. 
Matsui, T., Matsunaga, H., Ohya, K., Iwasaki, Y., Koshimune, K., Miyata, A., \& Kiriike, N. (2003). Clinical features in two cases with musical obsessions who successfully responded to clomipramine. Psychiatry and Clinical Neurosciences, 57(1), 47-51.

Müllensiefen, D., Fry, J., Jones, R., Jilka, S., Stewart, L., \& Williamson, V. J. (2014). Individual Differences Predict Patterns In Spontaneous Involuntary Musical Imagery. Music Perception, 31(4), 323-338. doi: 10.1525/mp.2014.31.4.323

Orozco, J. H. C. (2001). Rumores: voces que serpentean. Revista Latina de comunicación social 40, (9).

Retrieved from http://www.ull.es/publicaciones/latina/2001/latina40abr/108contreras.htm

Pearce, J. (2006). Synaesthesia. European neurology, 57(2), 120-124.

Pfizer, N., \& Andrade, C. (1999). Isolated musical obsessions. Indian journal of psychiatry, 41(1), 77.

Rheingold, H. (1987). Untranslatable words. The whole earth review (December 22).

Sacks, O. (2006). The power of music. Brain, 129(10), 2528-2532. doi: 10.1093/brain/awl234

Sacks, O. (2007). Musicophilia: Tales of Music and the Brain. London: Picador.

Sacks, O. (2011). Brainworms, sticky music, and catchy tunes. In M. Petracca \& M. Sorapure (Eds.) 4 Reading pop culture (pp. 99-104). New York: Prentice Hall.

Simner, J., Mulvenna, C., Sagiv, N., Tsakanikos, E., Witherby, S. A, Fraser, C.Scott, K. \& Ward, J. (2006). Synaesthesia: the prevalence of atypical cross-modal experiences. Perception, 35(8), 1024-1033.

Stewart, L., von Kriegstein, K., Warren, J. D., \& Griffiths, T. D. (2006). Music and the brain: disorders of musical listening. Brain, 129(10), 2533-2553. doi: 10.1093/brain/awl171

Taylor, S., McKay, D., Miguel, E. C, De Mathis, M. A., Andrade, C., Ahuja, N., Sookman, D., Kwon, J. S., Huh, M. J., \& Riemann, B. C. (2014). Musical obsessions: A comprehensive review of neglected clinical phenomena. Journal of anxiety disorders, 28(6), 580-589. 
Taylor, W.L. (1953). "Cloze procedure: A new tool for measuring readability." Journalism Quarterly, 30, 415-433.

Uga, V., Lemut, M. C., Zampi, C., Zilli, I., \& Salzarulo, P. (2006). Music in dreams. Consciousness and Cognition, 15(2), 351-357.

Vitorovic, D., \& Biller, J. (2013). Musical Hallucinations and Forgotten Tunes - Case Report and Brief Literature Review. Frontiers in Neurology, 4, 109. doi:10.3389/fneur.2013.00109

Wammes, M., \& Barušs, I. (2009). Characteristics of Spontaneous Musical Imagery. Journal of Consciousness Studies, 16, 37-61.

Ward, J. (2013). Synesthesia. Annual review of psychology, 64, 49-75.

Warren, J. D, \& Schott, G. D. (2006). Musical hallucinations in a musician. Journal of neurology, 253(8), 1097-1099.

Williamson, V. J., \& Jilka, S. R. (2014). Experiencing earworms: An interview study of involuntary musical imagery. Psychology of Music, 42(5), 653-670. doi: 10.1177/0305735613483848

Williamson, V. J., Jilka, S. R., Fry, J., Finkel, S., Müllensiefen, D., \& Stewart, L. (2012). How do “earworms" start? Classifying the everyday circumstances of Involuntary Musical Imagery. Psychology of Music, 40(3), 259-284.

Williamson V.J., Liikkanen, L.A., Jakubowski, K, \& Stewart, L. (2014). Sticky Tunes: How Do People React to Involuntary Musical Imagery? PLoS ONE 9(1): e86170. doi:10.1371/journal.pone.0086170

Williamson, V. J., \& Müllensiefen, D. (2012). Earworms from three angles: Situational antecedents, Personality predisposition and the quest for a musical formula. Paper presented at the 12th International Conference on Music Perception and Cognition, Thessaloniki, Greece. Retrieved from http://www.researchgate.net/profile/Victoria_Williamson/publication/235417649_Earwor 
ms_from_Three_Angles_Situational_Antecedents_Personality_Predisposition_and_the_Qu

est_for_a_Musical_Formula/links/0fcfd511618cb4f751000000.pdf

Table 1

Earworm translations in non-English languages

\begin{tabular}{ll}
\hline Language & Word or phrase \\
\hline Dutch & Oorworm \\
Finnish & Korvamato \\
French & Musique entêtante (Halpern \& Bartlett, \\
& 2011) \\
German & Ohrwurm (Eckert, 1979; Hemming, 2009) \\
Italian & Canzone tormentone (Halpern \& Bartlett, \\
& 2011) \\
& \\
Spanish & Cancion pegadiza (Cruz, 1998; Orozco, \\
\end{tabular}

Note: Ohrwurm also means earwig (Order Dermaptera) in German. Earworm in English can also refer to the corn earworm (Helicoverpa zea) which is an agricultural pest. 
Table 2

Definitions and characteristics of "earworm" and "Ohrwurm" displayed in chronological order of publication date.

\begin{tabular}{cll}
\hline \multicolumn{1}{c}{ Source } & \multicolumn{1}{c}{ Word/phrase } & \multicolumn{1}{c}{ Definition } \\
\hline Eckert (1979) & Ohrwurm & $\begin{array}{l}\text { "kurze Stücke aus } \\
\text { Melodien, die Einem für } \\
\text { einige Zeit nicht aus dem }\end{array}$ \\
& Kopf gehen" (p.40). \\
La Motte (1993) & Ohrwurm &
\end{tabular}

$\begin{array}{ll}\text { Bennett (2002) } & \begin{array}{l}\text { Earworm, } \\ \text { musical imagery } \\ \text { repetition }\end{array} \\ & \\ \text { Cunningham, Downie } & \begin{array}{l}\text { Earworm } \\ \text { \& Bainbridge (2005) }\end{array} \\ \text { Brown (2006) } & \begin{array}{l}\text { Perpetual music } \\ \text { track }\end{array}\end{array}$

"previously heard music that, while consciously unintended, repeats uncontrollably and pervasively in thought" (p. 5).

Other Characteristics

"earworm" is a literal translation of the German Ohrwurm, meaning a song that gets stuck in your head" (p. 475).

"having a melody be Especially just after stuck in their head for an listening to a piece of extended period of time" (p. 25).

Levitin (2006) Stuck song "songs get stuck in our syndrome heads. Scientists call these earworms ... or simply the stuck song syndrome" (p. 156).

Bailes (2007)

tune on the brain "everyday occurrence of having an involuntary "tune on the brain" (p. 555).

Sacks (2007) pp. 41-42 brainworms, sticky music

Can happen after one hearing and comes again and again into consciousness, can be annoying, often whistled or hummed out loud while performing.

music.

Earworm length: 15-30 seconds, more common in musicians, related to OCD.

Unintentional

Earworm length: three or four bars.

Duration: hours or days.
Liikkanen (2008)
Earworm
"mental replay of music" (p. 408).


Hemming (2009)

Liikkanen (2009)

Wammes \& Barušs (2009)

Beaman \& Williams (2010)

Halpern \& Bartlett (2011)

Sacks (2011)

Floridou, Williamson, Müllensiefen (2012)
Ohrwurm

Spontaneous musical imagery

"tunes, or so called earworms, caught in their [own] head" (p. 271). "song stuck in their own head...(p. 38).

Earworm

Earworm

Sticky music

"a short melody getting stuck in the mind and being heard repeatedly

"the experience of an inability to dislodge a song and prevent it from repeating itself in one's head" (p. 637).

"tunes that seem to get stuck in memory. This involuntary mental imagery is generally held to be annoying and/ or distracting" (p. 425).
Often sung, hummed, whistled or tapped along to; often occurring when unoccupied or where one might expect music to be heard; usually preferred or often heard music; the lyrics support the memory/recall; linked to situations from one's life; can occur immediately after exposure or some weeks later; initially pleasant later often become annoying.

Questionnaire refers to "music in my head" (p. $45)$.

"...not heard in months or years... never before heard in his life"( $p$. 37). Allows for the possibility that novel music may become repetitive and hence an earworm.

Endless repetition and the fact that the music in question may be irrelevant or trivial, not to one's taste, or even hateful. 


\begin{tabular}{|c|c|c|}
\hline $\begin{array}{l}\frac{\text { http://www.oed.com/ }}{\text { viewdictiyentry/Entry/ }} \\
\underline{318883} \text { (Second } \\
\text { edition, 1989; online } \\
\text { version December } \\
\text { 2011. ; accessed } 23 \\
\text { December 2011). }\end{array}$ & & $\begin{array}{l}\text { without the individuals's } \\
\text { will or conscious control" } \\
\text { (p. } 302 \text { ). } \\
\text { "a catchy tune or piece of } \\
\text { music (or occas. A word } \\
\text { or phrase) which } \\
\text { persistently stays in a } \\
\text { person's mind, esp. To } \\
\text { the point of irritation.". }\end{array}$ \\
\hline Hyman et al. (2013) & Intrusive song & $\begin{array}{l}\text { "...repetitively playing the } \\
\text { same song over and over } \\
\text { again" (p. 204). }\end{array}$ \\
\hline Liikkanen (2012a) & $\begin{array}{l}\text { Involuntary } \\
\text { musical imagery }\end{array}$ & $\begin{array}{l}\text { "involuntary musical } \\
\text { imagery refers to all } \\
\text { imagined musical } \\
\text { experiences that originate } \\
\text { without the subjects' } \\
\text { intention and are not } \\
\text { pathological"(p. 218). }\end{array}$ \\
\hline Liikkanen (2012b) & $\begin{array}{l}\text { Involuntary } \\
\text { musical imagery }\end{array}$ & $\begin{array}{l}\text { "INMI is defined as a } \\
\text { conscious experience of } \\
\text { reliving a musical memory } \\
\text { without } \\
\text { deliberatelyattempting to } \\
\text { do so. It is also known } \\
\text { byother colloquial names } \\
\text { such as earworms, } \\
\text { stickytunes, or tune in the } \\
\text { head phenomenon" (p. } \\
\text { 12). }\end{array}$ \\
\hline Liikkanen (2012c) & $\begin{array}{l}\text { Involuntary } \\
\text { musical imagery }\end{array}$ & $\begin{array}{l}\text { "commonly known as } \\
\text { "earworms" or the "tune } \\
\text { on the brain" } \\
\text { phenomenon and refers } \\
\text { to a non-clinical condition } \\
\text { of unintentionally reviving } \\
\text { the auditory image of a } \\
\text { tune" (p. 2). }\end{array}$ \\
\hline $\begin{array}{l}\text { Williamson et al. } \\
(2012)\end{array}$ & $\begin{array}{l}\text { Spontaneous or } \\
\text { involuntary } \\
\text { musical imagery, } \\
\text { "brain worms," } \\
\text { "sticky music", } \\
\text { "cognitive itch" }\end{array}$ & $\begin{array}{l}\text { "experience of a piece of } \\
\text { music that comes } \\
\text { unbidden into the mind } \\
\text { and repeats outside of } \\
\text { conscious control" (p. } \\
261) \text {. }\end{array}$ \\
\hline
\end{tabular}




\begin{tabular}{|c|c|c|c|}
\hline & $\begin{array}{l}\text { "stuck song } \\
\text { syndrome" }\end{array}$ & & \\
\hline $\begin{array}{l}\text { Williamson \& Jilka } \\
\text { (2013) }\end{array}$ & $\begin{array}{l}\text { Involuntarymusi } \\
\text { cal imagery, } \\
\text { INMI } \\
\text { ("earworms") }\end{array}$ & & $\begin{array}{l}\text { At least once per week, } \\
\text { faithful to original music, } \\
\text { can change over time, } \\
\text { feelings can be positive, } \\
\text { ambivalent, or negative, } \\
\text { loss of control, lessened } \\
\text { when concentrating on } \\
\text { complex tasks. }\end{array}$ \\
\hline Margulis (2014) & Earworms & $\begin{array}{l}\text { "those ditties that seem to } \\
\text { get irrevocably stuck in } \\
\text { your head" (p. 6) "tunes } \\
\text { that get stuck in our } \\
\text { head" (p. 66). }\end{array}$ & \\
\hline $\begin{array}{l}\text { Müllensiefen et al. } \\
\text { (2014) }\end{array}$ & $\begin{array}{l}\text { The colloquial } \\
\text { term associated } \\
\text { with INMI is } \\
\text { "earworms" }\end{array}$ & $\begin{array}{l}\text { "conscious, internal } \\
\text { experience of a musical } \\
\text { excerpt in the absence of } \\
\text { an external stimulus, } \\
\text { which then goes on to } \\
\text { repeat outside of } \\
\text { conscious will or control" } \\
\text { (p. } 323 \text { ). }\end{array}$ & $\begin{array}{l}\text { "other terms include } \\
\text { "brain worms," "sticky } \\
\text { music" (sacks, 2007), and } \\
\text { "spontaneous musical } \\
\text { imagery" (p. 323). }\end{array}$ \\
\hline $\begin{array}{l}\text { Williamson et al. } \\
\text { (2014) }\end{array}$ & $\begin{array}{l}\text { Involuntary } \\
\text { musical imagery } \\
\text { (INMI) } \\
\text { or,colloquially, } \\
\text { 'earworms' }\end{array}$ & & $\begin{array}{l}\text { "recall and replay of } \\
\text { musical imagery within } \\
\text { the mind's ear ... that } \\
\text { goes on to repeat on an } \\
\text { involuntary loop" (p. 1). }\end{array}$ \\
\hline
\end{tabular}


